\title{
The Relationship between the Equity Risk Premium, Duration and Dividend Yield ${ }^{1,2}$
}

\author{
Ruben D. Cohen ${ }^{3}$
}

\author{
Corporate Finance - Structured Products, Citigroup \\ 33 Canada Square, London E14 5LB United Kingdom
}

\section{Abstract}

Based on the fundamental equations of equity valuation, we derive here the relationship between the equity risk premium, duration and dividend yield. Aside from providing a logical foundation for the difference between the ex-ante and ex-post measures of the risk premium, the work leads to other outcomes, namely, but not specifically, (1) that the current, effective dividend policy is a signalling process, conveying information on expected profits, (2) an alternative valuation relation, stemming from the above-mentioned dividend policy, (3) another proof to the notion that the forward-looking equity risk premium is the expected dividend yield and, finally, (4) a straightforward, analytical explanation for the dividend puzzle, as well as for the observed decline in both, the dividend yield and the forward-looking equity risk premium.

\section{Introduction}

Equity valuation is a topic of primary importance to both, academia and industry. The whole purpose of valuing equity is to generate forecasts of price, given interest rate, earnings, dividends, etc.

Although simplistic in concept and construct, the theories that underlie the existing valuation techniques are indeed elegant, and, consequently, they fill a central role in all theoretical and practical settings.

${ }^{1}$ April 2002. http://rdcohen.50megs.com/ERPabstract.html.

${ }^{2}$ I express these views as an individual, not as a representative of companies with which I am connected.

${ }^{3}$ E-mail: ruben.cohen@citigroup.com - Phone:+44(0)207986 4645.
However, for reasons discussed later, none of these theories seem to work in the short run, although they do display sound validity in the long run. It is due to this that many practitioners, as well as theoreticians, tend to twist and turn these simple, yet classic, concepts as they attempt to apply them to short-run situations. In the process, these efforts have led to much confusion, causing many to lose touch with the original messages behind these models. As most academic-minded practitioners would attest, the practice-oriented literature is particularly notorious for being cluttered with such presentations.

With the above in mind, we have written this paper to, hopefully, achieve several objectives. First, we intend to put into perspective the basic models of equity valuation and examine their underlying notions and limitations. This is then followed by an assessment of their long-run historical validity and significance.

Second, we combine these models, as they are and without any modifications, to explore the consequences of some key hypothetical scenarios. Along with serving as the bases for a couple or so of forthcoming propositions, these scenarios would also provide us with simple, yet logical, explanations for (1) why firms pay dividends and (2) the apparent decline in the dividend yield - two academic, as well as practical, issues that crop up repeatedly.

The third, and final, objective is to bring into the picture the notions of the equity risk premium and duration, as we derive a fundamental 
relationship between the two, taking into account as well the dividend yield. This last result could have important implications since it breaks down the highly subjective, and often controversial, equity risk premium into a few measurable components. The overall impact could, thus, help render the notion easier to understand, discuss and, more importantly, implement in practice.

\section{Previous works}

Theoretical and empirical studies tying the equity risk premium [or returns] to the dividend yield abound in the literature. Although each of these areas has been investigated separately before, the core of the interest in their relationship appears to have begun through a series of papers in the 1980s (see, for example, Rozeff, 1984; Campbell and Shiller, 1988; Fama and French, 1988\&1989). There is no need to mention that this interest has remained strong and persistent ever since (Marsh and Power, 1999; and many others after).

The myriad of works looking exclusively at the risk premium have focused primarily on its estimation. The resulting papers cover mainly the different methods of approach, which range from the use of accounting fundamentals (Tippett, 2000) to asset pricing models (Mehra and Prescott, 1985) and analyst growth forecasts (Harris, 1986), etc. [see, for instance, Arnott and Ryan, 2001; Welch, 2000; and references therein, among many others]. Most, if not all, of these have relied on either heuristic or some type of regression analysis to estimate the risk premium. Curiously, all these cases detect major discrepancies between the forward and backward-looking measures of the risk premium. However, the theme common to all is that while the historical equity risk premium has remained, more or less, stable throughout the many decades of its observation, the forward-looking one has followed a declining trend, especially over the latter half of the 20th century (Jahnke, 1999; Arnott and Ryan, 2001).

The dividend yield, likewise, has been treated before separately. The main issues surrounding this have ranged from determining the factors that affect the dividend yield (Hunt, 1977; among others) to trying to figure out the optimal dividend policy ${ }^{4}$ (Cyert et al, 1996; Fan and Sundaresan, 1999; among others).

The literature also contains a sizeable amount on the link between the equity risk premium and the dividend yield. The relation between the two has been found either, to be in the form of an identity (Rozeff, 1984; Cohen, 2000a), or to include other factors as well, such as earnings yield, interest rates, etc. (Fama and French, 1988; Sorensen and Arnott, 1988; Asness, 2000; among others), as demonstrated via regressions.

Here, also, we discuss the connection between the dividend yield and the risk premium, although through a methodology different from the conventional. Our approach basically (1) builds on the notion of market equilibrium, (2) introduces a logical, as well as analytical, way for differentiating between the backward and forward-looking measures of the risk premium and, finally, (3) provides inter-related explanations for sev- eral outstanding dilemmas, in particular, the dividend puzzle and the persistent decline in the dividend yield, as well as in the forward-looking equity risk premium. Interestingly, it is shown that all these issues emanate from one common root - namely, our inability to see into the future and predict, even on a short-term basis, movements in the economy and the markets.

\section{Background and methodology}

It is best to start here with a summary of a couple of papers on the subjects of the long-term risk premium and relative valuation [see Cohen (2000a\&b)]. For convenience, we have, in addition to following a similar approach and replicating the nomenclature here, also reproduced certain relevant features, such as some of the equations and graphs that already appear in the above-mentioned papers. ${ }^{5}$

3.1. The Equations of Equity Valuation and the Concept of Equilibrium Valuation of equity, in the classical sense, is generally conducted in three ways. We start this section by introducing each of the three ways and then proceed with developing our model. It is important, however, to note that, although the three methods are fundamentally different, they do share a common principle, which is to set the discount rate on equity equal to the expected return on equity.

Let us begin with the first equation, which states that the market's discount rate on equity, or, as mentioned above, its "expected" ${ }^{6}$ return on equity, $R_{M}(t)$, is

$$
R_{M}(t) \equiv \ln \left(\frac{S_{f}(t)}{S(t)}\right)+\frac{\delta_{f}(t)}{S(t)}
$$

where the first term on the right-hand side represents the expected capital gains and the second the expected dividend yield. Here, $S(t)$ is the current price, and $S_{f}(t)$ and $\delta_{f}(t)$, respectively, are the one-year-ahead forecasts of [or expected] price and dividends, all generated today, at time $t$.

The second valuation equation incorporates the well-known Gordon's growth model. Re-arranged, the model is expressible by:

$$
R_{I}(t) \equiv \ln \left(\frac{\delta_{f}(t)}{\delta(t)}\right)+\frac{\delta_{f}(t)}{S(t)}
$$

where $R_{I}(t)$ is, again, the discount rate, as computed by the dividendreceiving investor, and $\delta(t)$ is the current dividend paid at time $t$. Equation 3.2, therefore, asserts that the discount rate is equal to the expected growth in dividends plus the expected dividend yield. ${ }^{7}$

We finally come to the last fundamental relationship, which is

$$
R_{F}(t)=\frac{E_{f}(t)}{S(t)}
$$


Equation 3.3 is the most basic form of the discounted-cash-flow relationship, with $R_{F}(t)$ being the expected return on equity [or the discount rate from the perspective of the profit-generating firm] and $E_{f}(t)$ the expected net profit after interest and tax, but before dividends [i.e. equity earnings]. In relation to the above equations, it is important to bear in mind that, while Equation 3.1 is only a definition, Equations 3.2 and 3.3 are well-established valuation models, albeit all conceptually dissimilar to each other.

It is now useful to also write down the implied rates of return on equity, namely $\tilde{R}_{M}(t+1), \tilde{R}_{I}(t+1)$ and $\tilde{R}_{F}(t+1)$, all in analogy with Equations 3.1-3.3, respectively. These are expressed in terms of the actual, measured quantities, so that

$$
\begin{gathered}
\tilde{R}_{M}(t+1) \equiv \ln \left(\frac{S(t+1)}{S(t)}\right)+\frac{\delta(t+1)}{S(t)} \\
\tilde{R}_{I}(t) \equiv \ln \left(\frac{\delta(t+1)}{\delta(t)}\right)+\frac{\delta(t+1)}{S(t)}
\end{gathered}
$$

and

$$
\tilde{R}_{F}(t)=\frac{E(t+1)}{S(t)}
$$

where $S(t+1), \delta(t+1)$ and $E(t+1)$, correspond, in their respective order, to the actual price, dividends paid and equity earnings a year later than $t$. Consequently, if the markets were completely free of unexpected changes and fully efficient - i.e., with all forecasts being accurate - the one-year-ahead expected rates of return, $R_{M}(t), R_{I}(t)$ and $R_{F}(t)$ produced today, would precisely equal their counterparts, $\tilde{R}_{M}(t+1), \tilde{R}_{I}(t+1)$ and $\tilde{R}_{F}(t+1)$ realised one year later.

With these equations in place, therefore, we re-state the concept of market equilibrium ${ }^{8}$ as:

$$
R_{M}(t)=R_{I}(t)=R_{F}(t)
$$

and make a note of its three underlying components, which are

$$
\begin{aligned}
& R_{M}(t)=R_{I}(t) \\
& R_{I}(t)=R_{F}(t)
\end{aligned}
$$

and

$$
R_{M}(t)=R_{F}(t)
$$

For reasons given earlier (Cohen, 2000a), we now assume that the oneyear-ahead forecasts of price, dividends and earnings - i.e. $S_{f},(t), \delta_{f}(t)$ and $E_{f}(t)$ - are accurate reflections of their actual counterparts, $S(t+1)$, $\delta(t+1)$ and $E(t+1)$, measured a year later. With this, therefore, we go on to provide a fairly detailed summary of the market's behaviour over the last 130 years.

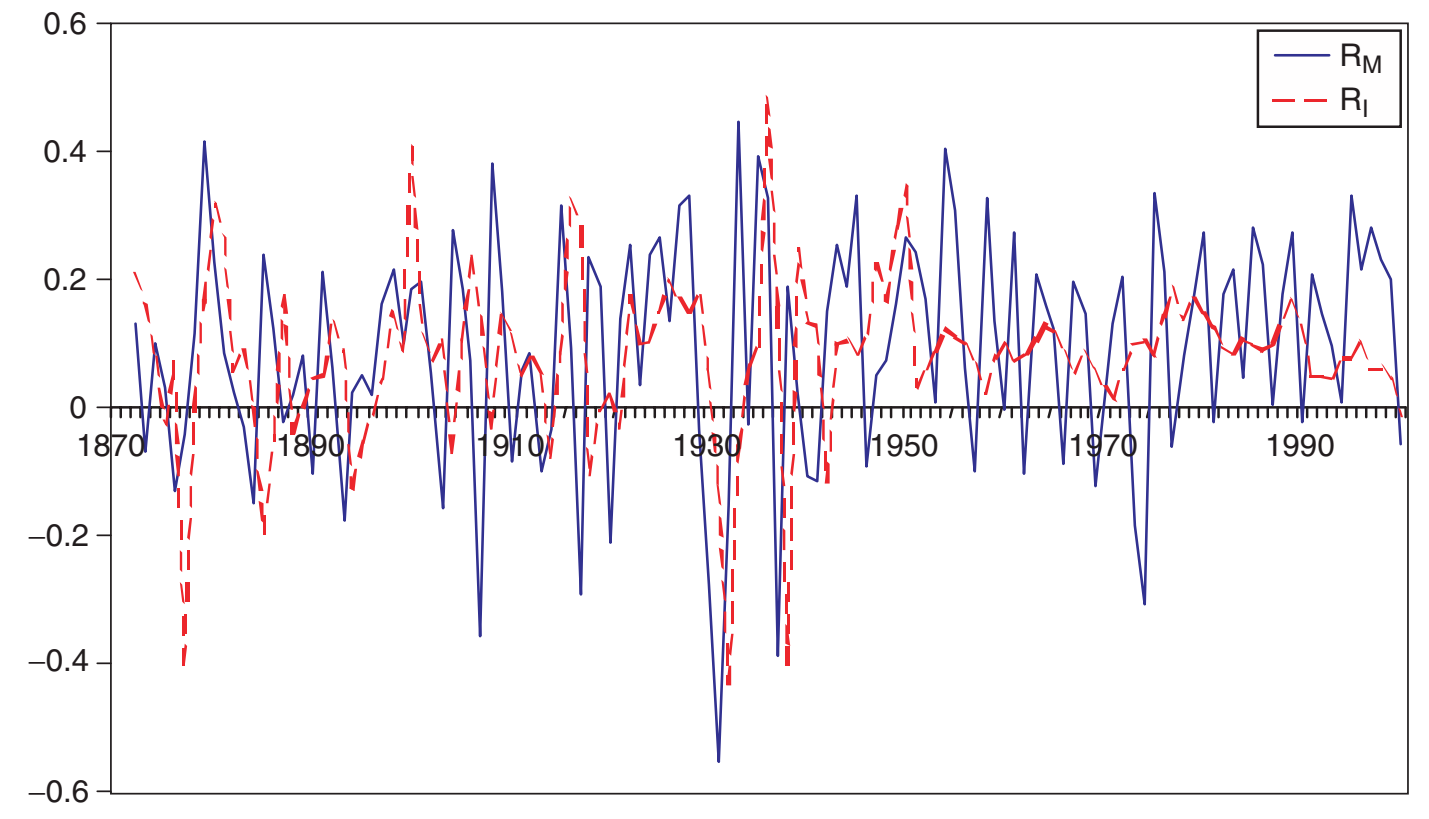

Fig. 1a . The different rates of return on equity, $R_{I}$ and $R_{M}$, calculated using Equations 3.1 and 3.2, respectively, and plotted together as functions of time. This is to assess the validity of Equation 3.6a. 


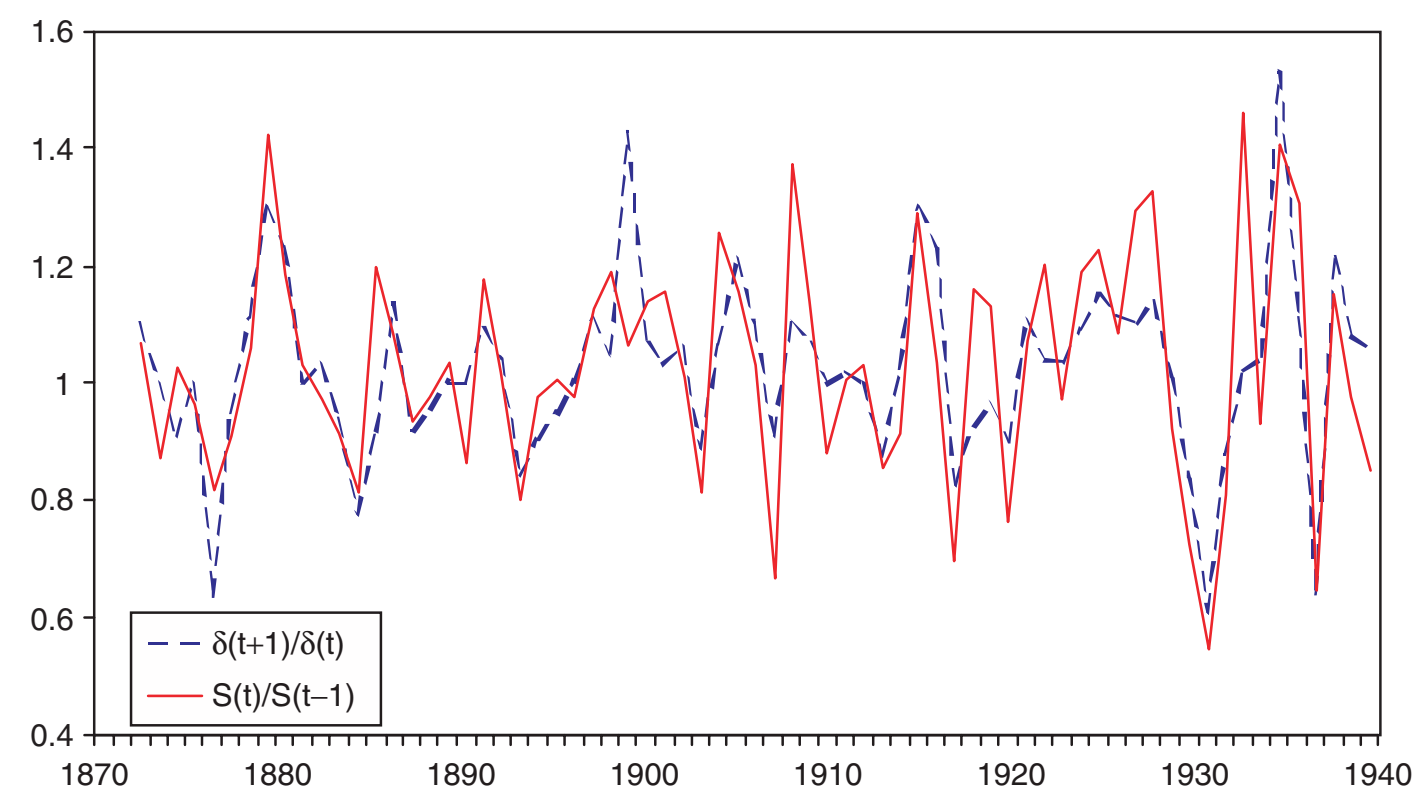

Fig. 1b. The ratios $\delta(t+1) / \delta(t)$ and $S(t) / S(t-1)$ for the $S \& \mathrm{P}$ Composite Index plotted together in the same graph The high correlation during the time period 1870-1940 suggests that a constant dividend policy was in place.

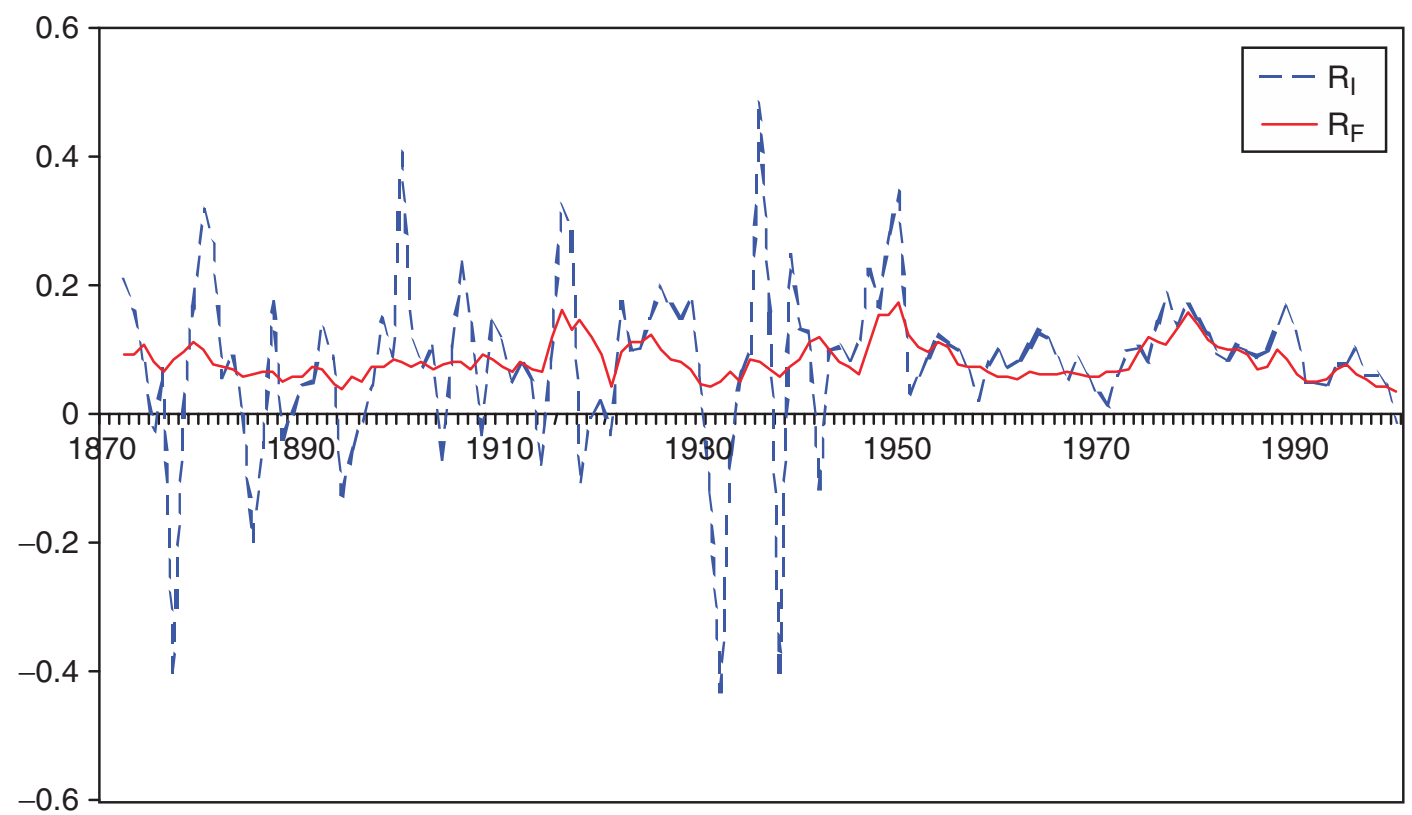

Fig. 2. The different rates of return on equity, $R_{I}$ and $R_{F}$, calculated using Equations 3.2 and 3.3, respectively, and plot ted together as functions of time. This is to assess the validity of Equation $3.6 \mathrm{~b}$ 


\subsection{The Behaviour of the S\&P Market from 1870 to 2000}

We have, so far, written down the governing equations of equity valuation, re-stated the notion of equilibrium [based on Cohen (2000a)] and, finally, broken down the relation into its individual components, Equations $3.6 \mathrm{a}-\mathrm{c}$. Our next goal is to assess the historical validity and significance of each of these components, hopefully to establish precisely why the market behaved as it did. For this, we reproduce Figures 1-3, where all data relating to $S, \delta$ and $E$ have been obtained from Shiller's tables of the historical S\&P Composite Price Index ${ }^{9}$ (Shiller, 2002) ${ }^{10}$.

Figure 1a displays a plot of $R_{M}(t)$ [or $\left.\tilde{R}_{M}(t+1)\right]$ and $R_{I}(t)$, both versus time, $t$, on one graph. This allows us to examine the validity of Equation 3.6a, leading to the observation that, while the two rates lie, more or less, closer to one another during the period 1870-1940, they clearly deviate after that.

To shed light on this, we insert the definitions for $R_{M}$ and $R_{I}$, as given by Equations 3.1 and 3.2, into 3.6a, and obtain:

$$
\frac{S(t+1)}{S(t)}=\frac{\delta(t+1)}{\delta(t)}
$$

after some re-arrangement. The above may, in turn, be re-written as:

$$
\frac{\delta(t+1)}{S(t+1)}=\frac{\delta(t)}{S(t)}=\cdots=\text { constant }
$$

Although, at first glance, Equation 3.7b appears to reflect a constant dividend yield policy, it is not quite so. Properly portrayed, such a policy would have the time frame for the price shifted back by one year - i.e.

$$
\frac{\delta(t+1)}{S(t)}=\frac{\delta(t)}{S(t-1)}=\cdots=\text { constant }
$$

or

$$
\frac{S(t)}{S(t-1)}=\frac{\delta(t+1)}{\delta(t)}
$$

presented in analogy with 3.7a.

Considering the relative, but insufficient, nearness of $R_{E}$ and $R_{I}$ in Figure 1a prior to 1940, we plot instead in Figure 1b the ratios $S(t) / S(t-1)$ and $\delta(t+1) / \delta(t)$, both against time, $t$, to establish whether or not a constant dividend yield policy was in place throughout 1870-1940. In this case, we note that not only a tighter correlation exists between the two $[0.73$ versus the original 0.11], but a statistically significant one-to-one relationship appears to hold as well ${ }^{11}$. This supports the notion that a constant dividend policy was indeed in place between 1870 and 1940

Having confirmed the dominant role of the constant dividend yield policy [or roughly Equation 3.6a] in the S\&P market from 1870 to 1940 we now proceed, in the same way, to establish the structure underlying the market after 1940. As before, we do this by evaluating the validity of the components of the equilibrium relation, Equation 3.5.

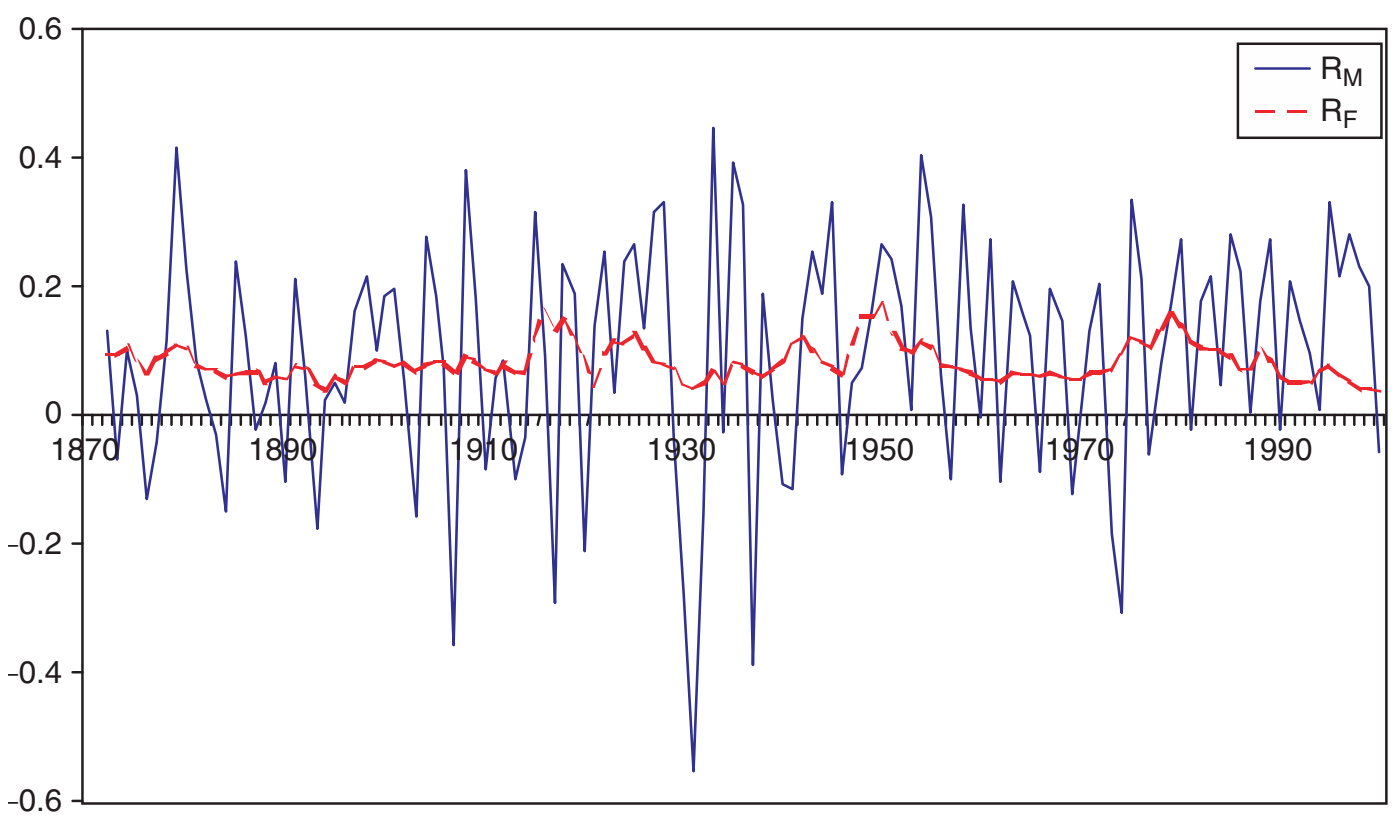

Fig. 3. The different rates of return on equity, $R_{M}$ and $R_{F}$, calculated using Equations 3.1 and 3.3, respectively, and plotted together as functions of time. This is to assess the validity of Equation 3.6c. 
Figure 2, which depicts $R_{I}$ and $R_{F}$ versus time, clearly portrays a structural change in the behaviour of $R_{I}$, taking place during the $1940 \mathrm{~s}$ decade. This is obvious from the way the two rates of return, $R_{I}$ and $R_{F}$, which behaved differently prior to 1940 , began to move more in line with one another after around $1950^{12}$ [allowing for a 10-year transition, from 1940-1950].

To explain, we substitute Equations 3.2 and 3.3 into $3.6 \mathrm{~b}$ and get

$$
\frac{\delta_{f}}{\delta}=\frac{1+E_{f} / S}{1+\delta / S}
$$

upon approximating $\ln \left(\delta_{f} / \delta\right)$ as $\left\{\delta_{f} / \delta\right\}-1$ and re-arranging. Very simply, Equation 3.9 states that, since around 1950, the dividend policy within the market has been devised in such a way that dividend payments were made to carry information on earnings prospects. This is in sharp contrast to the pre-1940 regime, during which the policy was strictly one of constant dividend yield.

Hence, what underlies Equation 3.9 is a mechanism that relates to market efficiency and the flow of information. In this instance, the firm relays news to the investor about its future, expected profits, $E_{f}$, when it announces the expected dividends, $\delta_{f}$, for the next year. This, subsequently, allows the investor to value the equity more in line with the firm's valuation, as generated by Equation 3.3.

By now, we have established that the market's behaviour was driven by a policy of constant dividend yield up to around 1940, after which an efficiency-related mechanism took over. Each regime, in fact, comprises one component of the equilibrium relation.

Before proceeding any further, it would be useful to look also at the third, and last, component of Equation 3.5, which is Equation 3.6c, and work out its essence. We do this by substituting Equations 3.1 and 3.3 into 3.6c and getting:

$$
\ln \left(\frac{S_{f}}{S}\right)_{(3.10)}=\frac{E_{f}-\delta_{f}}{S}
$$

which is the well-known notion of "re-investment equals growth."

Thus, from Figure 3, which displays both, $R_{M}$ and $R_{F}$, versus time, it is evident that the notion of reinvestment equals growth has never held over the short run ${ }^{13}$. This also goes on to say that this simple, intuitive idea is not one of short, or even medium, term, but one of very long term. Even then, it would strictly be on a mean-reversion basis. The conclusion here is, therefore, that the three components of Equation 3.5 have never tracked one another simultaneously, which leads to the argument that, within the scope of our definition, the market has never achieved "full" equilibrium, at least over the last 130 years.

\subsection{An Alternative Valuation Relation}

A major problem with utilising the valuation relations given by Equations 3.1-3.3 is that the discount rate is not known. Therefore, it would be helpful to have an alternative relationship that bypasses the need for the discount rate.

To get to this, we return to Equation 3.9, which depicts the current dividend policy, and solve for the price, $S(t)$ - i.e.

$$
S(t)=\frac{E_{f}(t)-\delta_{f}(t)}{\ln \left[\delta_{f}(t) / \delta(t)\right]}
$$

after reverting to the logarithmic form for dividend growth. Equation 3.11 tells us that, given forecasts of earnings and dividends, $E_{f}(t)$ and $\delta_{f}(t)$, respectively, as well as the current dividend paid, $\delta(t)$, one should be able to estimate the value of equity without having to rely on the discount rate. The absence of a discount rate in the above should, therefore, enable one to accomplish the task of valuation more objectively.

From a practitioner's point of view, dealing with Equation 3.11 might be more convenient because it is common for forecasts of both, earnings and dividends, to be made available. The earnings forecast is generally

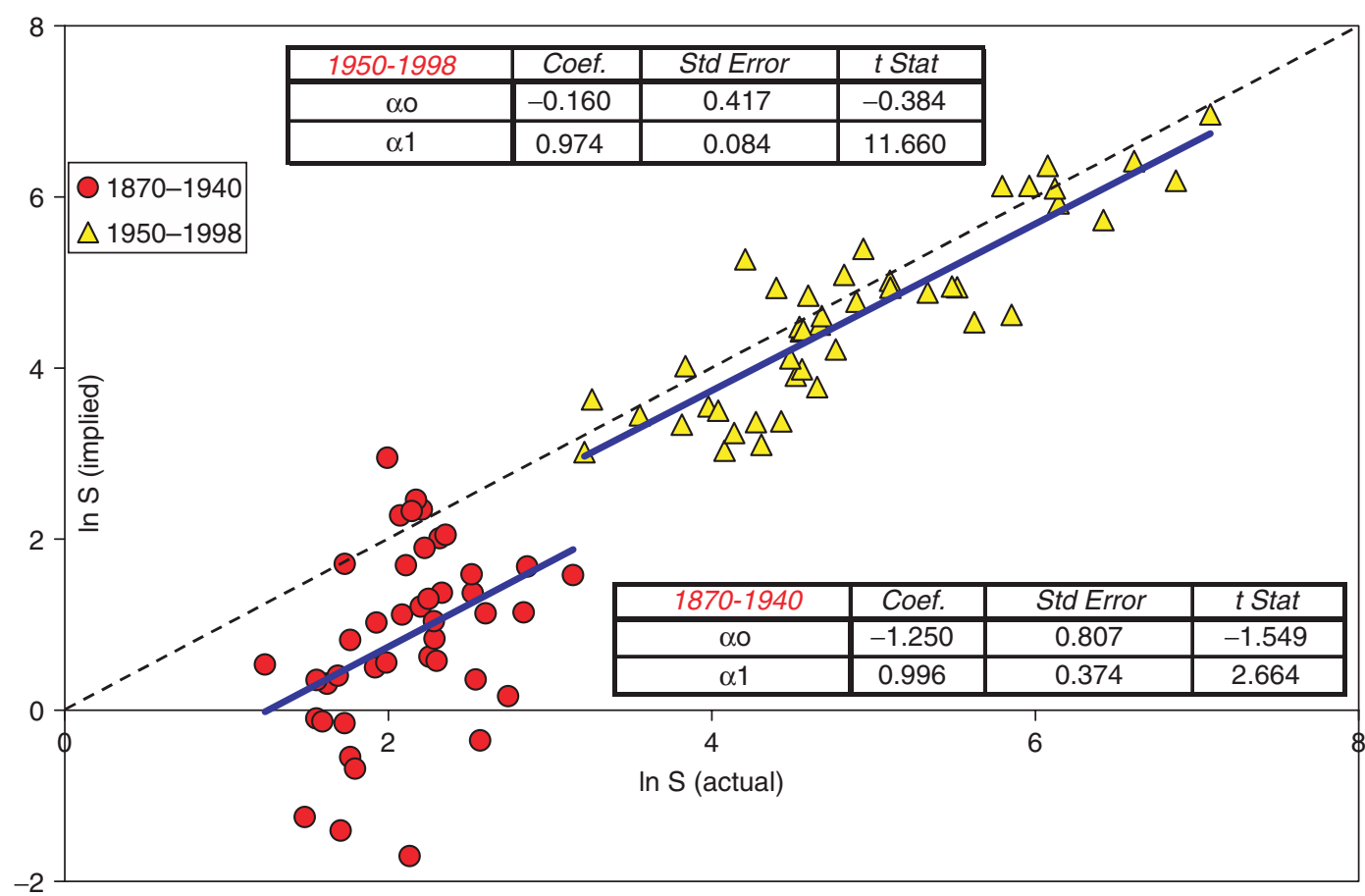

Fig. 4 Examining the alternative valuation relationship. Here, the [logarithm of the implied price, as obtained from Equation 3.12, is compared to the actual. The line going through each set of data points, belonging to the periods 1870-1940 and 1950-1998, is the best-fit straight line of the regression equation 3.13, whose preliminary statistics are also presented in the tables. Note that the statistics further confirm the division between the two regimes. 
provided by analysts, while dividends are typically announced in advance by the firm.

Let us now express 3.11 in terms of the realised values, so that:

$$
S_{\text {implied }}(t)=\frac{E(t+1)-\delta(t+1)}{\ln [\delta(t+1) / \delta(t)]}
$$

where $S_{\text {implied }}(t)$ corresponds to the calculated value of equity, as implied by the current and one-year-ahead figures for the earnings and dividends. To assess the validity of the above, we write down the following regression:

$$
\ln S_{\text {implied }}(t)=\alpha_{0}+\alpha_{1} \ln S(t)+\varepsilon(t)
$$

where $S(t)$ is the actual price, $\alpha_{0}$ and $\alpha_{1}$ the coefficients and $\varepsilon(t)$ the error. Therefore, if the relationship were to apply, particularly in the period between 1950 and now, $\alpha_{0}$ must be statistically insignificant and $\alpha_{1}$ should be significantly close to 1 . The error, $\varepsilon(t)$, must also pass certain tests, but these shall remain out of the scope of this work, as our focus here is not to delve deeply into statistical methodologies.

The results of the regression, which are both illustrated in Figure 4 and presented in the underlying tables, are divided into two parts. One part reflects the pre-transition period, from 1870 to 1940, and the other the post-transition period, from 1950 to about the present. It should be noted that, in cases where negative or undefined values for $S_{\text {implied }}(t)$ were obtained - e.g. when $\delta(t+1) \leq \delta(t)$ - the data points have been excluded altogether. All in all, the preliminary statistics, as well as the proximity of the data to the diagonal line in Figure 4, indicate a reasonable fit for the post-transition period, which could justify the potential suitability of Equation 3.11 as an alternative relationship for equity valuation. ${ }^{14}$

\section{Limiting cases}

We focused in Section 3 on the actual, historical behaviour of the S\&P Composite data. These data are, without a doubt, full of uncertainties, comprising all types of fluctuations and risk.

These uncertainties arise from one, and only one, source - namely, our inability to forecast in advance any natural or man-made occur rences. ${ }^{15}$ Such events include famines, wars, recessions, technological advances, as well as a myriad other phenomena. In view of this, we go on to the next section and define a couple of limiting, hypothetical scenarios that should allow us to proceed further.

\subsection{The Fully Efficient Market}

Subsequent to the above, we live in a world where economic and financial markets are so erratic that, to be successful as an investor, one requires not only a great deal of information and knowledge, but also a significant amount of luck. It, thus, follows that as markets become even more efficient and competitive, and investors acquire access to comparable amounts of quality information, the luck factor gets to outweigh the knowledge factor, leading ultimately to the situation where investing resembles more a casino. The scenario described here takes us to the boundaries of a fully efficient market, where pure luck dominates. This, notwithstanding, is both, a limiting case, as well as a strongly hypothetical situation.

Let us now turn a full 180 degrees and pose the following, contrasting question: "how would the markets behave in the other extremity, where no uncertainties and change exist?" It will turn out that the answer to this, which is derived next, holds the key to several of our findings.

\subsection{The Hypothetical Case of No Uncertainties and Change}

To describe the hypothetical scenario of a market with no uncertainties and related volatility and change, it is necessary to refer to Equation 3.5, which portrays our version of equilibrium. Note that, owing to reasons presented shortly, each of the underlying rates would carry with it a risk premium of its own.

By definition, the equity risk premium, which is included in the three expected rates of return - i.e., $R_{M}, R_{I}$ and $R_{F}$ - and readily described in Section 3.1, is expressible by

$$
\begin{gathered}
R_{M}=b+R_{P M} \\
R_{I}=b+R_{P I}
\end{gathered}
$$

and

$$
R_{F}=b+R_{P F}
$$

where $b$ is some sort of a "risk-free" rate, if such a thing exists, ${ }^{16}$ and $R_{P M}, R_{P I}$ and $R_{P F}$, respectively, are the premiums belonging to the market, the investor and the firm. Since $R_{M}, R_{I}$ and $R_{F}$ in $4.1 \mathrm{a}-\mathrm{c}$ are the expected rates of return, then their associated premiums, $R_{P M}, R_{P I}$ and $R_{P F}$, are also expected or forward looking.

Similarly, we also need to define the historical, or ex-post, risk premiums. These are given by

$$
\begin{gathered}
\tilde{R}_{M}=b+\tilde{R}_{P M} \\
\tilde{R}_{I}=b+\tilde{R}_{P I}
\end{gathered}
$$

and

$$
\tilde{R}_{F}=b+\tilde{R}_{P F}
$$

where this time, in contrast with Equations $3.4 \mathrm{a}-\mathrm{c}$, we have used the "tilde" to distinguish between expected [forward looking] and historical [backward looking].

Consequently, we have introduced here three different types of risk premiums. This, essentially, evokes the possibility that the three historical rates of return may not be equal to each other all at the same time - i.e., 
when Equations $3.6 \mathrm{a}-\mathrm{c}$ are not all satisfied simultaneously. In relation to the S\&P data, for instance, the validity of Equation 3.6b, along with the irrelevance of 3.6a and 3.6c, throughout the last 50 years or so ${ }^{17}$ [see, for example, Figure 2] suggests that the historical risk premium calculated by the investor is similar to that observed by the firm - i.e.,

$$
R_{P I}=R_{P F}
$$

whereas the historical market risk premium, as obtained from Equations 3.4a and 4.2a, acts as an entity all by its own.

It, therefore, follows that if we were to evaluate the historical risk premium using either Equation 3.2 or 3.3, we should arrive at consistent results. But if, instead, we were to do it through 3.1, we should end up with a different number. The reason for this is simply that as the underlying structure of the market has shifted from Equation 3.6a to 3.6b, so has the structure of the risk premium. This, we believe, is the leading cause behind much of the discrepancies in the risk premiums, as they are calculated from the various valuation relations, 3.1 to 3.3.

This now enables us to describe the outcome of our second limiting case, which is an imaginary world that is subject to no changes, uncertainties and, thus, fluctuations. Prior to moving on, however, it would be necessary to develop first the conditions that create such an environment, and then attempt to derive its implications and consequences.

\subsubsection{Re-visiting the Notion of the Discounted-cash-flow Valuation}

Before trying to put into perspective the potential causes of steady-state equilibrium, we need to include a few words on the discounted-cash-flow relationship, Equation 3.3. There are two assumptions that underlie this equation, namely that (1) the stream of all future earnings, $E_{f}$, is uniform, equal to currently generated $E_{f}(t)$, and (2) the discount rate, $R_{F}$, also remains constant throughout, equal to the current value, $R_{F}(t)$.

Let us go now to Equation 3.3 and express it as:

$$
\begin{aligned}
S(t) & =\frac{E_{f}(t)}{R_{F}(t)} \\
& =\sum_{n=1}^{\infty} \frac{E_{f}}{\left(1+R_{F}\right)^{n}}
\end{aligned}
$$

which we re-write as:

$$
\begin{aligned}
S & =\frac{E_{f}}{1+R_{F}}+\frac{1}{1+R_{F}} \sum_{n=1}^{\infty} \frac{E_{f}}{\left(1+R_{F}\right)^{n}} \\
& =\frac{E_{f}}{1+R_{F}}+\frac{S}{1+R_{F}}
\end{aligned}
$$

Multiplying both sides of 4.4 by $\left[1+R_{F}\right]$ yields:

$$
\left[1+R_{F}\right] \times S-S=E_{f}
$$

or

$$
\frac{S_{f}-S}{S}=\frac{E_{f}}{S}
$$

after recognising that, under a constant discount rate, the expected price, $S_{f}$, of one year from today equals today's price, $S$, multiplied by $\left[1+R_{F}\right]$.

Equation $4.5 \mathrm{~b}$ is, interestingly, similar to 3.10 , but with the dividend yield removed. As it shall be demonstrated shortly, this result takes us into the realms of the steady-state equilibrium, which we focus on next.

\subsubsection{The Steady-state Equilibrium and its Impact on the Risk Premium} and Dividend Yield

Carrying on with the above arguments, we consider here an environment where no changes, certain and uncertain, occur. Here, the resulting interest rate, which shall be denoted by $b^{*}$, remains constant in time and, thus, should reflect the true risk-free rate. This, therefore, leads to a flat and horizontal yield curve, which has always been, and shall remain constant for ever. Additionally, all investment instruments - stocks, bonds, etc. - should yield at the same rate, each equal to the risk-free rate, $b^{*}$. And, finally, the economy has always grown and will keep on growing according to the golden rule - that is, growth rate equals $b^{*}$. With these in place, we present our first proposition as:

Proposition 1 - In a world that is free of all changes, uncertainties and their associated volatility - historical, current, and forward-looking - the risk premium becomes identically equal to zero.

Proposition 1, therefore, implies that

$$
R_{P M}=R_{P I}=R_{P F}=0
$$

as well as

$$
\tilde{R}_{P M}=\tilde{R}_{P I}=\tilde{R}_{P F}=0
$$

leading to a steady-state equilibrium, whereby all rates of return are equal to $b^{*}-$ i.e.

$$
\tilde{R}_{M}=\tilde{R}_{I}=\tilde{R}_{F}=R_{M}=R_{I}=R_{F}=b^{*}
$$

The impacts of 4.6 and 4.7 on the valuation equations may now be assessed by incorporating them into $4.1 \mathrm{a}-\mathrm{c}$ and $4.2 \mathrm{a}-\mathrm{c}$, and the results into both, the ex-ante and ex-post relationships, Equations 3.1-3.3 and $3.4 \mathrm{a}-\mathrm{c}$, respectively. This yields:

$$
\begin{aligned}
& \ln \left(\frac{S_{f}(t)}{S(t)}\right)=b^{*}-\frac{\delta_{f}(t)}{S(t)} \\
& \ln \left(\frac{\delta_{f}(t)}{\delta(t)}\right)=b^{*}-\frac{\delta_{f}(t)}{S(t)}
\end{aligned}
$$

and 



\subsection{The Diminishing Dividend Yield}

The persistent decline in the S\&P's dividend yield, especially throughout the latter half of the 20th century, is well-documented. The data in Figure 5 clearly portray this, as the dividend yield is shown to fall from its historical average value of about $5.5 \%$ in 1950 to its present $1.1 \%$. We will propose here a logical and, hopefully, plausible, explanation for this.

Let us recall that the current dividend policy, effective since 1950, is one of signalling, as dictated by Equation 3.9. For convenience, we write it here again, but with the time parameter included:

$$
\frac{\delta_{f}(t)}{\delta(t)}=\frac{1+E_{f}(t) / S(t)}{1+\delta(t) / S(t)}
$$

Multiplying both sides of 3.9 by $S(t-1) / S(t)$ and defining the current dividend yield, along with its time- $t$ generated expected counterpart, as $\hat{\Delta}(t)$ and $\hat{\Delta}_{f}(t)$, respectively, as:

and

$$
\hat{\Delta}(t) \equiv \frac{\delta(t)}{S(t-1)}
$$

$$
\hat{\Delta}_{f}(t) \equiv \frac{\delta_{f}(t)}{S(t)}
$$

we obtain:

$$
\frac{\hat{\Delta}_{f}(t)}{\hat{\Delta}(t)}=\frac{1+E_{f}(t) / S(t)}{S(t) / S(t-1)+\hat{\Delta}(t)}
$$

after some re-arrangement. Assuming a steady environment again, in accordance with Section 4.2.2, and incorporating Equations 4.8c, 4.9a and 4.10, all in conjunction with Propositions 1 and 2, we obtain:

$$
\frac{\hat{\Delta}(t+1)}{\hat{\Delta}(t)}=\frac{1+b^{*}}{1+b^{*}+\hat{\Delta}(t)}
$$

after setting the expected dividend yield, $\hat{\Delta}_{f}(t)$, equal to its realised counterpart, $\hat{\Delta}(t+1)$.

Equation 4.13 is a difference equation, whose solution manifests the evolution of the theoretical dividend yield. To solve, it requires an initial condition, which we shall take to be the mentioned figure of 5.5\%, beginning in 1950. It needs, in addition, a value for the true, steadystate, risk-free rate, $b^{*}$, which we shall take here to be $5 \%$. This number will never be known, as interest rates have always been, and shall always remain, volatile. Never the less, $5 \%$ is perhaps a fair number ${ }^{19}$. In theory, therefore, and according to Equation 4.13, the dividend yield in 1951 would be:

$$
\hat{\Delta}(t=1951)=\frac{5.5 \% \times(1+5 \%)}{1+5 \%+5.5 \%}=5.23 \%
$$

Note the decay from $5.5 \%$ in 1950 to $5.23 \%$ the following year.
The above calculations have been carried out to the present, with results also included in Figure 5, along with the observed dividend yield. It is interesting to note that, although the comparison is not that tight, the overall relationship is satisfactory given the simplicity of the underlying theory. From this, therefore, we are able to conclude that as long as the current, effective dividend policy, as given by Equation 3.9, is in place, the dividend yield should continue to fall asymptotically towards zero.

\section{The dividend puzzle}

The issues surrounding the dividend puzzle occupy a special niche in the finance literature. These debates have lingered on and on, as there has always been disagreement among theoreticians, as well as practitioners, on the question of why firms pay dividends (e.g. Black, 1976 \& 1996; Bernheim, 1991; Frankfurter, 1999; among many others). Here, in light of what we have discussed so far, we also attempt to provide an answer to this dilemma.

The dividend puzzle has evolved from one of Modigliani and Miller's [M\&M] theorems (1959 and 1961), which is directed at the irrelevance of dividends in the valuation of shares. As this concept is covered well in the literature, we shall avoid getting into its details and, instead, highlight the concerns that arise from it.

The message behind this M\&M theorem is that dividends, from the investor's point of view, should have no effect, whatsoever, on the process of valuing equity. On this basis, therefore, it should not matter to the investor whether firms pay dividends or not.

The above conclusion, nevertheless, has proven futile as, in the majority of the cases, investors do demand some type of a dividend payment. The reasons for this have been attributed to a wide range of factors, reflecting, among others, behavioural issues, tax-related matters, asymmetric information and signalling. We, as well, shall offer a rationale for this puzzle.

Our solution to the dividend puzzle may be broken down into three parts.

1. First, and foremost, markets pay a finite dividend yield [rather than dividends] because of intrinsic uncertainties. Having already proven that a market that functions in a perpetually steady-state environment, such as the one protrayed in Section 4, need not provide a dividend yield because the investor will not demand it ${ }^{20}$, the dividend yield should, thereby, act as a premium to cover uncertainties and their associated risks. This, obviously, carries with it the implication that the dividend yield is related, in one way or another, to the risk premium - a matter to be discussed in more detail in Section 6.

2. Second, and equally important, is the dividend policy - i.e. if dividends were irrelevant, as per M\&M's theorem, then the dividend policy should also be irrelevant. Accordingly, therefore, the market should be able to implement any type of policy at will. 


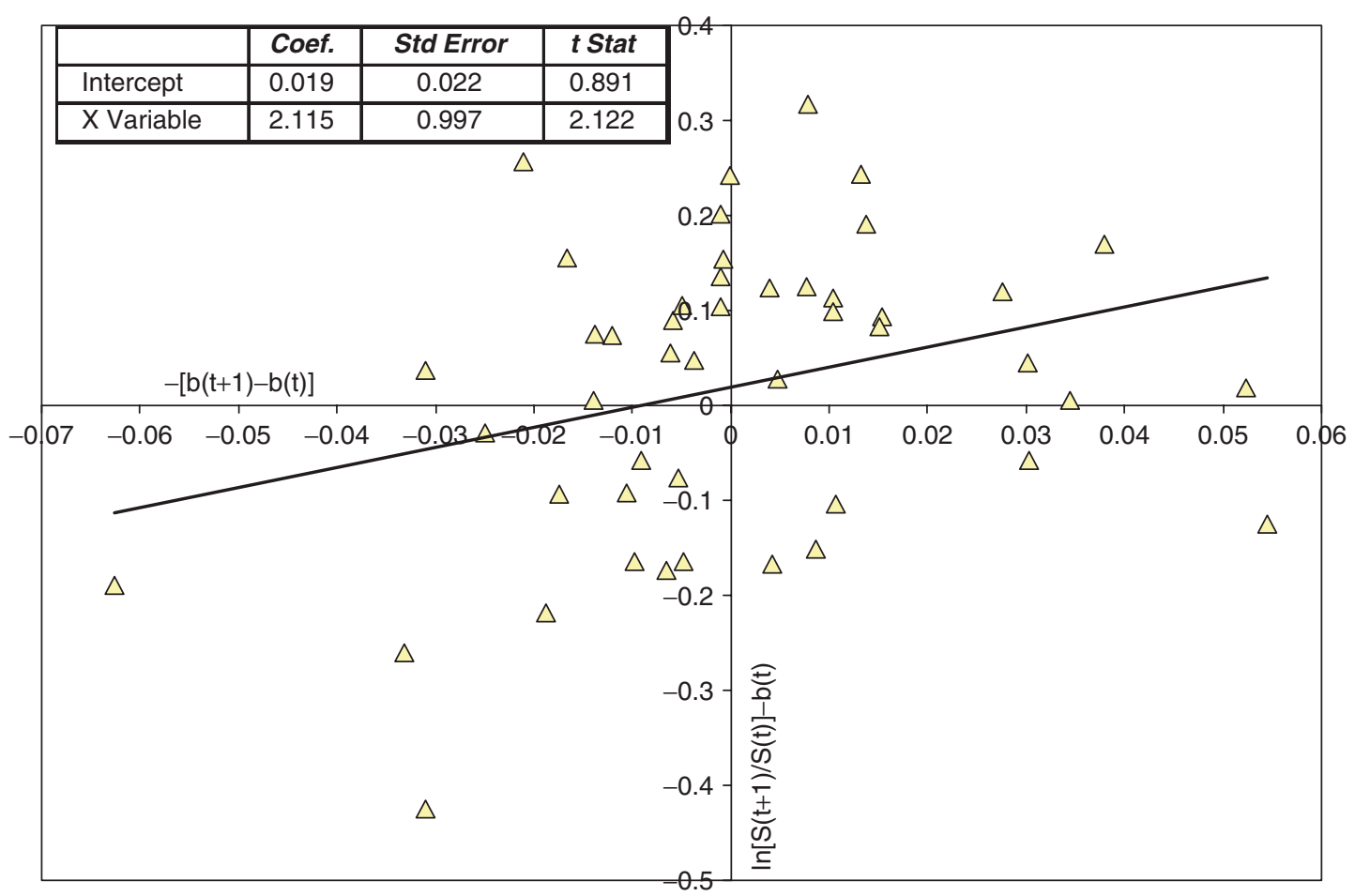

Fig. 6. Estimating the implied equity duration, $D_{s}$, using Equation 6.5. The solid line is the best-fit straight line. The value of about 2.115 years, which is the slope, is an average over about 50 years of data presented here [1953-2000]. Consequently, it fails to account for the shifts in equity duration that might have occurred during the time period.

Has this ever been the case? Our work shows that, to the contrary, the dividend policy has acquired well-defined structures throughout the last 130 years or so of the S\&P Composite Price Index. First came the constant dividend yield policy, followed then by a signalling-related policy, the latter being the one in effect today.

3. Finally, why has the dividend yield been on a declining trend over the past few decades? We took a shot at explaining this in Section 4.3, but a more intuitive answer is as follows. If, for instance, we examine more closely Equation 4.5b, which is an outgrowth of 3.3 we note that it reflects the market's rate of return [e.g. Equation 3.1], but with the dividend yield set equal to zero. Evidently, therefore, its implementation, particularly starting from around 1950, into creating the current dividend policy, should inevitably lead to a falling dividend yield. As a result, the dividend yield should continue to decline towards zero as long as this dividend policy is in place.

In conclusion, our answer to the dividend puzzle is three fold. Firstly, markets pay a finite dividend yield because of inherent uncertainties.
Secondly, the dividend policy is a signalling process, informing the investor of expected profits [this is in line with Bernheim (1991)]. And thirdly, the dividend yield has been on a declining path because the current dividend policy, which has been in effect over the last few decades, contains within it the discounted-cash-flow relationship, Equation 3.3 As this equation intrinsically presumes a zero dividend yield [compare Equation $4.5 \mathrm{~b}$ with 3.10$]$, then any policy that emanates from it must lead to a diminishing dividend yield.

\section{The relation between the equity risk premium, duration and dividend yield}

Sections 4 and 5 hint on a possible connection between the equity risk premium and the dividend yield. Although such a relationship, particularly between the forward-looking risk premium and the expected dividend yield, has already been proposed (Rozeff, 1984; Cohen, 2000a), we offer here yet another proof, utilising a different approach.

Let us now return to Section 4.2.2, where we argued that a steadystate environment should lead to a diminishing dividend yield. Note that 
this situation is applicable as well to forward-looking valuation, where all future discount rates and earnings are presumed constant.

Inserting Equation 4.10 into $4.9 \mathrm{a}$ and $4.9 \mathrm{~b}$, and carrying the result to the limit of differential calculus, yields ${ }^{21}$ :

$$
\left(\frac{\partial \ln S}{\partial t}\right)_{b=b^{*}=\text { cons tant }}=b^{*}
$$

Without having to solve the above ${ }^{22}$, we recognise that it implies that the price, $S$, is a function of both, the constant interest rate, $b^{*}$, as well as time, $t$. Simply, therefore, we express this as:

$$
\ln S=\ln S\left(b^{*}, t\right)
$$

Taking this further, we generalise $6.2 \mathrm{as}^{23}$.

$$
\ln S=\ln S(b, t)
$$

where this time we allow for changes in the interest rate - i.e. $b=b(t)$.

The leap from 6.2 to 6.3 enables variations in the economy to enter through the interest rate and, subsequently, impact the price. Thus, while Equation 6.2 is restricted to our imaginary steady-state world, where the time-value of money is the only means for growth, Equation 6.3 brings into play also the impact of time-dependent changes in economic and other factors, which were not included earlier.

With this in place, the total differential of Equation 6.3 becomes

$$
\frac{d \ln S}{d t}=\left(\frac{\partial \ln S}{\partial t}\right)_{b}+\left(\frac{\partial \ln S}{\partial b}\right)_{t} \frac{d b}{d t}
$$

which we re-write as

$$
\frac{d \ln S}{d t}=b-D_{s} \dot{b}
$$

after incorporating Equation 6.1 and defining $\dot{b}$ as $d b / d t$ and the stock duration, $D_{s}$, as the sensitivity of price to interest rate - i.e.,

$$
D_{s} \equiv-\left(\frac{\partial \ln S}{\partial b}\right)_{t}
$$

Equation 6.5, thereby, provides the fundamental relationship between the expected growth in price, interest rate, stock duration and the expected change in interest rate.

A quick run on the statistics behind Equation 6.5 results in Figure 6. This figure plots the yearly growth in the stock price less the 10-year government bond yield [which is being used here as a proxy for $b$ ] against the negative of the yearly change in $b$, i.e. $\dot{b}$. While the former is calculated as $\ln [S(t+1) / S(t)]-b(t)$, the latter is computed as the negative of the quantity $[b(t+1)-b(t)]$. Evidently, the effective equity duration, $D_{s}$, averaged over the roughly 50 years of the data, drops out as the coefficient of the regression, whose value happens to be around 2.12 years over the given time period ${ }^{24}$. The intercept, which, according to Equation 6.5, is supposed to be zero, does indeed turn out to be a statistically insignifi- cant 0.019 . It should be mentioned that the data for the US government bond yields are the December figures from the years 1953 to 2000, all obtained from the Fed's website.

The equity risk premium may now be brought into the picture by inserting Equations 3.1 and 4.1a into 6.5. ${ }^{25}$ This yields

$$
R_{P M}=\frac{\delta_{f}}{S}-D_{s} \dot{b}_{f}
$$

which associates the ex-ante equity risk premium, $R_{P M}$, with the expected dividend yield, $\delta_{f} / S$, duration, $D_{s}$, and the expected variation in interest rate, $\dot{b}_{f}$. On the other hand, the historical counterpart to the above would instead utilise the historical dividend yield, along with the observed variations in the interest rate.

The distinction between the historical and expected, therefore, leads to our third proposition, being:

Proposition 3 - The forward-looking investor values financial securities according to constant parameters, all going forward.

This proposition follows for two reasons. One is that our forecasting abilities, not taking into account any additional, insider information, are, without any doubt, limited. Since we are simply not able to see beyond the very near future, if at all, virtually all parameters - i.e. interest rate, expected earnings, expected dividends, etc. - that are incorporated into the valuation techniques are always held constant going forward. Examples of this are particularly evident in the classical valuation relations, Equations 3.1-3.3, provided here.

Another reason supporting the proposition is that the risk-free rate going forward should, by definition, remain constant [see the first paragraph of Section 4.2.2]. Any other rate that is assumed to vary with time simply cannot be risk free. Subsequently, if the current interest rate were to be considered the risk-free rate, then all its associated, expected changes going forward, - i.e. $\dot{b}_{f}$ - must strictly be taken as equal to zero.

The above should, therefore, considerably simplify the forward-looking risk premium relationship, given by Equation 6.7. If, for instance, by virtue of Proposition 3, the interest rate and expected dividend yield, $b$ and $\delta_{f} / S$, respectively, are presumed constant going forward, then

$$
\dot{b}_{f}=0
$$

which leaves a forward-looking risk premium that is equal to the expected dividend yield. This finding is consistent with Rozeff's (Rozeff, 1984). On the other hand, the historical risk premium would include, in addition, the observed variations in the interest rate, $\dot{b}$. This coupled with a non-zero equity duration, $D_{s}$, therefore, introduces an additional term into the equation. This, in fact, explains why the historical and forward-looking measures of the equity risk premium have rarely matched one another ${ }^{26}$ and, furthermore, why they should never be expected to converge as long as markets and, subsequently, interest rates behave erratically. 


\section{FOOTNOTES \& REFERENCES}

4. The optimal dividend policy is supposed to maximise the price of the stock. 5. A more comprehensive definition of all these variables could be found in Cohen (2000a)

6. Here, by "expected" we mean the one-year-ahead forecast.

7. We have used in Equations 3.1 and 3.2 the logarithmic, instead of the difference, form to describe growth

8. This was introduced in Cohen (2000a) in the form of a proposition.

9. All data points are the December figures taken from the monthly collection.

10. http://aida.econ.yale.edu/ shiller/data.htm

11. The statistics related to this correlation, which were found to be highly significant, are included in Cohen (2000a).

12. The statistics of this co-movement, which were also found to be highly significant, can be found as well in Cohen (2000a).

13. By short to medium term, we mean a period of up to 10 years. This, of course, is in comparison to the 130-year history of the available data.

14. The quality of the resulting valuation obviously depends on the quality of the earnings forecast, as well as on whether or not the underlying dividend policy follows Equation 3.9 .

15. It is, unfortunately, common to have analysts consistently come up with the claim that they are in possession of a "short-run" forecasting model.

16. The notion of the risk-free rate, $b$, is also surrounded by controversy, especially in the empirical literature. Although there is little argument that $b$ should be based on a government-issued security, questions abound as to what maturity it should take.

Another problem, which is more fundamental in nature, addresses the "riskiness" of $b$ - that is, how could government securities be considered risk free when they are, as with any other type of security, volatile and impossible to predict.

17. We shall refer to this as "the more recent history"

18. Note that this is consistent with the conclusions based on the discounted-cash-flow valuation, Equation 4.5b.

19. Equation 4.13 is not very sensitive to $b^{\star}$ if $b^{\star}<<1$, which is, very likely, always the case.

20. Based on Propositions 1 and 2 .

21. It is important to stress here that either set of equations, $4.8 a-c$ or $4.9 a-c$, will lead to a similar outcome in a constant environment.

22. The solution is exponential growth, which relates to the time-value of money, with the interest rate held constant.

23. This was introduced in Cohen (2000b) as a new approach to relative valuation. 24. Obviously, the value of 2.12 years calculated here for the equity duration is only an objective measure, based on an average over 50 years of data. In comparison, a more comprehensive computation of duration would perhaps require breaking down the 50 year time period into its different regime components and extracting the duration associated with each regime.

25. The one-year expected growth in price, $\ln \left(S_{f} / S\right)$, has been taken here to be equivalent to its differential counterpart, $d \ln S / d t$.

26. See, for instance, Cornell (1999) for matters related to the discrepancy between the historical and the forward-looking risk premiums.

27. all related to the long history of the S\&P Composite Price Index

28. The main restriction is that it applies under the dividend policy defined by

Equation 3.9.

29. Also available at: $h t t p: / / r d c o h e n .50 m e g s . c o m / p a p e r s . h t m /$
Arnott, R.D. and Ryan, R.J. (Spring 2001) "The Death of the Risk Premium," Journal of Portfolio Management, pp. 61-74.

- Asness, C.S. "Stocks versus Bonds: Explaining the Equity Risk Premium," Financial Analysts Journal 56, pp. 96-113.

- Bernheim, B.D. (1991) "Tax Policy and the Dividend Puzzle," RAND Journal of Economics 22, pp. 455-476.

- Black, F. (1976) "The Dividend Puzzle," Journal of Portfolio Management 2, pp. 5-8. - (1996) "The Dividend Puzzle," Journal of Portfolio Management, Special

Issue, pp. 8-12.

- Campbell, J.Y. and Shiller, R. (1988) "Stock Prices, Earnings and Expected Dividends," Journal of Finance 43, pp. 661-676.

- Cohen, R.D. (2000a) "The Long-run Behaviour of the S\&P Composite Price Index and its Risk Premium," Internal Memo, Citigroup Asset Management (formerly SSB Citi Asset Management Group). ${ }^{27}$

- Cohen, R.D. (2000b) "An Objective Approach to Relative Valuation," Internal Memo, Citigroup Asset Management (formerly SSB Citi Asset Management Group). ${ }^{29}$

- Cornell, B. The Equity Risk Premium: The Long-run Future of the Stock Market, John Wiley and Sons, Inc., NY, 1999.

- Cyert, R., Sok-Hyon, K. and Kumar, P. (1996) “Managerial Objectives and Firm Dividend Policy: A Behavioral Theory and Empirical Evidence," Journal of Economic Behavior \& Organization 31, pp. 157-174.

- Fama, E.F. and French, K.R. (1988) "Dividend Yields and Expected Stock Returns,"

Journal of Financial Economics 22, pp. 3-25.

- Fama, E.F. and French, K.R. (1989) "Business Conditions and Expected returns on stocks and Bonds," Journal of Financial Economics 25, pp. 23-50.

- Fan, H. and Sundaresan, S. (1999) “Debt Valuation, Renegotiations and Optimal

Dividend Policy," working paper, Graduate School of Business, Columbia University.

- Frankfurter, G.M. (Summer 1999) "What is the Puzzle in 'The Dividend Puzzle'?"

Journal of Investing, pp. 76-85.

- Harris, R.S. (1986) “Using Analyst's Growth Forecasts to Estimate Shareholder

Required Rates of Return," Financial Management 15, p. 58.

- Hunt, L.H. (1977) “Determinants of the Dividend Yield," Journal of Portfolio

Management 3, p. 43

- Jahnke, W. (1999) "The Vanishing Equity Risk Premium," Journal of Financial Planning 12, pp. 32-36

Marsh, I.W. and Power, D. (1999) "A Panel-based Investigation into the Relationship Between Stock Prices and Dividends," FERC Working Paper.

- Mehra, R. and Prescott, E. (1985) "The Equity Risk Premium Puzzle," Journal of Monetary Economics 15, pp. 145-161.

Modigliani, F. and Miller, M.H. (1959) “The Cost of Capital, Corporation Finance and the Theory of Investment: Reply," American Economic Review 49, pp. 655-669.

Miller, M.H. and Modigliani, F. (1961) “Dividend Policy, Growth and the Valuation of Shares," Journal of Business 34, pp. 411-433.

口 Rozeff, M.S. (1984) "Dividend Yields are Equity Risk Premiums," Journal of Portfolio Management 11, pp. 68-75.

- Sorensen, E.H. and Arnott, R.D. (1988) “The Risk Premium and Stock Market Performance," Journal of Portfolio Management 14, pp. 50-55.

- Tippett, M. (2000) "Discussion of Estimating the Equity Risk Premium Using Accounting Fundamentals," Journal of Business Finance and Accounting 27, pp. 1085-1106

Welch, I. (2000) "Views of Financial Economists on the Equity Premium and on Professional Controversies," Journal of Business 73, pp. 501-537. 
Very briefly, therefore, here is an intuitive account of why, since around 1950, the dividend yield has been declining in tandem with the ex-ante equity risk premium. Since that time, the market has adopted a dividend policy that has built into it an efficient means for informing the investor on expected profits. This transfer of information thereby reduces related uncertainties, which, in turn, leads to a drop in the associated risk. The drop in the uncertainties and risk, presumably, allows the investor to forego at least part of the dividends in favour of having them re-invested. And so goes the process that causes both, the forward-looking risk premium and the expected dividend yield, to decline in unison.

\section{Conclusions}

The three fundamental equations of equity valuation were brought together here in an attempt to explain some of the outstanding questions that concern the equity risk premium and dividends ${ }^{27}$. This led to several interesting conclusions, which are outlined below.

1. The combination of the three equations leads to our concept of market equilibrium, which consists of three components. Each of these components relates to a specific and well-known idea in finance theory - namely, the constant-dividend yield policy, information efficiency and the notion of re-investment equals growth. With regards to the available data, it is shown that, while the market was previously governed by a constant-dividend yield policy, information efficiency is now effectively what drives the current dividend policy. The concept of re-investment equals growth has, on the other hand, never played a leading role in the short-tomedium term movements in the market.
2. The existing dividend policy further leads to an alternative valuation relationship for equity. This relationship bypasses the need for the discount rate and uses, instead, forecasts of earnings and dividends, both of which are widely available in the practical world. A preliminary assessment of the validity of this relationship is shown in Figure 4, which suggests that, subject to the restictions imposed on $i^{28}$, it is indeed reasonabe and, perhaps, worth pursuing as a line of research.

3. Another key conclusion pertains to the dividend puzzle. Our answer to this is three fold. Firstly, investors demand a dividend yield because of uncertainties. Secondly, the market provides dividends to convey information on expected profits. And, lastly, the decline in the dividend yield, especially over the last few decades, is a consequence of the current, effective dividend policy. Thus, as long as this policy is in place, the dividend yield should continue to fall.

4. The failure of one of the components of the equilibrium relationship - namely, the notion of re-investment equals growth - to hold means that the historical risk premium obtained from Equation 3.1 should be different from that extracted from 3.2 This also explains why the risk premiums calculated from the different relations never seem to match one another.

5. As presented by Equation 6.7, the equity risk premium is related directly to the dividend yield, duration and changes in the interest rate. Therefore, while the ex-post risk premium could be computed from the historical values of the above parameters, the ex-ante may be obtained by equating to zero any future changes in the interest rate. This way, the interest rate, going forward, is held constant, in coherence with the fundamental valuation equations.

6. Now, since the absence of any knowledge on future fluctuations in the interest rates allows us to disregard them and set them equal to zero, the ex-ante equity risk premium then becomes identically the expected dividend yield [see Equation 6.7]. Accordingly, this should also explain why the former is on a declining trend as well. As with the dividend yield, therefore, the ex-ante risk premium should continue to fall as long as the current dividend policy is in effect. 